\title{
EFFICIENCY MEASUREMENT OF CLOUD SERVICE PROVIDERS USING NETWORK DATA ENVELOPMENT ANALYSIS
}

\author{
Majid Azadi, Ali Emrouznejad, Fahimeh Ramezani, Farookh Khadeer Hussain
}

\begin{abstract}
An increasing number of organizations and businesses around the world use cloud computing services to improve their performance in the competitive marketplace. However, one of the biggest challenges in using cloud computing services is performance measurement and the selection of the best cloud service providers (CSPs) based on quality of service (QoS) requirements (Duan, 2017). To address this shortcoming in this article we propose a network data envelopment analysis (DEA) method in measuring the efficiency of CSPs. When network dimensions are taken into consideration, a more comprehensive analysis is enabled where divisional efficiency is reflected in overall efficiency estimates. This helps managers and decision makers in organizations to make accurate decisions in selecting cloud services. In the current study, the nonoriented network slacks-based measure (SBM) model and conventional SBM model with the assumptions of constant returns to scale (CRS) and variable returns to scale (VRS) are applied to measure the performance of 18 CSPs. The obtained results show the superiority of the network DEA model and they also demonstrate that the proposed model can evaluate and rank CSPs much better than compared to traditional DEA models.
\end{abstract}

Index Terms: Cloud service providers (CSPs); Performance measures; Efficiency measurement; Data Envelopment Analysis; Network slacks-based measure (SBM) model.

\section{INTRODUCTION ${ }^{1}$}

Cloud services have become a new paradigm in the last decade. Unlike conventional approaches to the provision of storage, compute and network resources to meet the customer's needs, cloud services provide customers with on-demand services that are available over a network. The major types of cloud services are Software as a

- Majid Azadi, Centre for Artificial Intelligence and School of Computer Science, Faculty of Engineering and Information Technology, University of Technology Sydney, NSW 2007, Australia,majid.azadi@student.uts.edu.au

- $\quad{ }^{1}$ Corresponding author: Ali Emrouznejad, Aston Business School, Aston University, Birmingham, UK,a.emrouznejad@aston.ac.uk

- Fahimeh Ramezani, Centre for Artificial Intelligence and School of Computer Science,
Service (SaaS), Infrastructure as a Service (IaaS) and Platform as a Service (PaaS). For each of these services, the cloud architecture offers many benefits including economies of scale, quick bug fixes, potential cost-savings through the "pay-asyou-go" model, and the fast deployment of new features (Atmaca, 2016; Elgendy et al. 2018). Due to these benefits, increasingly business organizations are hosting their applications on

Faculty of Engineering and Information Technology, University of Technology Sydney, NSW 2007, Australia, fahimeh.ramezani@uts.edu.au

- Farookh Khadeer Hussain, Centre for Artificial Intelligence and School of Computer Science, Faculty of Engineering and Information Technology, University of Technology Sydney, NSW 2007, Australia, farookh.hussain@uts.edu.au 
cloud infrastructures in order to save huge investment or up-front costs (Kumar and Agarwal, 2014).

However, there are some serious problems in business organisations using cloud services. One of the most serious problem is how to evaluate and select the best cloud service providers (CSPs) from the large number available. The number of CSPs who offer cloud computing as-a-utility has increased exponentially in recent years, providing more options from which the customers may choose. This rapid growth of cloud services means that customers interact with unknown CSPs to carry out transactions and tasks. In such conditions, a rating system can help them to choose a CSP that meets their requirements more efficiently and effectively. If an appropriate service provider is not selected, critical problems may occur, such as lowquality service delivery by the CSP and its potential business impact on the cloud consumer. Thus, there is a need for organizations to evaluate and select a suitable CSP according to standard and accepted criteria related to Quality of Service (QoS) (Supriya et al. 2016).

Data envelopment analysis (DEA) is a powerful linear programming technique to measure the performance of a number of homogenous decisionmaking units (DMUs). Because of its considerable advantages, DEA has become a popular tool for performance measurement and benchmarking in many areas over the last two decades. For example, Shao and Lin (2002) proposed a DEA model for technical efficiency analysis of information technology investments. Emrouznejad et al. (2010) proposed a DEA model to measure information and communication technology (ICT). Azadi and Farzipoor (2013) proposed a combination of quality function deployment (QFD) and imprecise DEA for efficiency evaluation in the healthcare sector. Martínez-Núñez and Pérez-Aguiar (2014) presented an integrated DEA-model assessment for the efficiency analysis of information technology and online social networks management. Mirhedayatian et al. (2014) proposed a fuzzy network DEA for the performance measurement of green supply chains. Azadi et al., (2015) presented a fuzzy DEA for evaluating and selecting sustainable suppliers. Widiarto et al. (2017) proposed observing choice of loan methods in notfor-profit microfinance using DEA. Fathi and Farzipoor (2018) proposed a bi-directional network DEA model to evaluate the sustainability of the distributive supply chains of transport companies. Huang (2018) presented a hybrid network DEA to assess the performance of tourism supply chains.

Despite the numerous advantages and the widespread application of DEA and network DEA in many areas as powerful decision-supporting instruments, their applications in the cloud computing is scarce and infancy. To address this shortcoming, the main purpose of the current study is to demonstrate a rarely-utilized non-parametric analysis technique, named network DEA, in the context of cloud services. This is because although DEA and network DEA continue to enjoy increasing popularity, a considerable number of publications and research fail to make the most of the potential capacities of these well-accepted techniques. Many published applications of DEA and network DEA have shown that potential improvements will be gained at the organizational level after applying these commonly used techniques. 
The rest of this paper is organized as follows. In Section 2, the literature review is presented. Section 3 details the methodology and the preliminaries. Section 4 discusses the evaluation of the proposed model. The results and a discussion are given in Section 5. The implications of this research are presented in section 6 . The conclusion is given in section 7 with suggestions for future work.

\section{Literature ReVIEW}

This section is structured as follows. Section 2.1 presents the literature on efficiency measurement of CSPs and cloud services. Section 2.2 presents the literature on the implementation of DEA in cloud environment.

\section{EFFICIENCY MEASUREMENT OF CSPS AND Cloud SERVICES}

Several approaches have been used for the evaluation and selection of CSPs. Choudhury et al. (2012) proposed a Static Service Ranking System (SRS) with static and dynamic states to evaluate and select cloud services. The static system evaluates and ranks cloud services without considering the cloud service customers' requirements, whereas the dynamic system utilizes a weighted aggregation approach for some of the main attributes, such as throughput, reliability, availability, security, cost and user feedback in order to rank cloud services. Ghosh et al. (2015) proposed a framework called SelCSP (Select Cloud Service Provider) to assess and select trustworthy and competent CSPs. The proposed model estimates trustworthiness with respect to contextspecific, dynamic trust and reputation feedback. The proposed model also computes the competence of a CSP based on the transparency of service-level agreements (SLAs). Rajarajeswari and Aramudhan (2015) proposed the Poincare Plot method (PPM) based mathematical model to rank CSPs in a federated cloud management system. The proposed model finds the most appropriate CSP for the incoming request in an efficient manner. Singh and Sidhu (2017) addressed the problem of evaluating trusted CSPs. They proposed a compliance-based multi-dimensional trust evaluation system (CMTES) that enables cloud service customers to determine the level of trust for CSPs from different perspectives. The proposed method can help cloud service customers who want to select a CSP from a number of CSPs based on QoS requirements.

Huang et al. (2012) proposed a hybrid multicriteria decision analysis (MCDM) model based IaaS cloud improvement method to increase the service quality of the IaaS cloud. Three components comprise the proposed hybrid MCDM model: decision-making trial and evaluation laboratory (DEMATEL), grey relational analysis (GRA) and the analytic network process (ANP). Garag et al. (2013) developed a ranking model called the service measurement index (SMI) cloud which ranks cloud services using the analytic hierarchy process (AHP) and a developed standard known as SMI metrics. Sahri et al. (2014) utilized AHP to help cloud customers evaluate and select the best database as a service (DBaaS) cloud provider. AHP consists of some key QoS attributes, distributed on three levels. Relative importance weights and rates are selected on a scale of 1-9. Menzel et al. (2014) applied AHP and a genetic algorithm for IaaS cloud assessment. The proposed model allows cloud customers to assess and select the best IaaS cloud providers based on certain QoS criteria. Supriya et al. (2016) compared various trust estimation methods using the MCDM to evaluate and rank CSPs offering IaaS. The trust estimation of service providers uses the Cloud Service Measurement Initiative Consortium (CSMIC) parameters prioritized based on finance, security and performance criteria. Alabool and 
Mahmood (2016) proposed a framework for evaluating the level of trust for CSPs. In their proposed model, they used several components, including the diagrammatic trust tree and hybrid evaluation and ranking technique combining fuzzy sets, simple additive weights and important performance analysis (IPA).

Although lots of works have been done on performance measurement problems and selection of CSPs and cloud services, the existing approaches suffer from some limitations and drawbacks such as requiring complex calculations, being effort-intensive, being time-consuming, ranking irregularities. Furthermore, existing approaches are unable to differentiate between a large number of CSPs a in a highly intense competition cloud marketplace.

\section{The IMPLEMENTATION OF DEA IN CLOUd ENVIRONMENT}

There are a very few research on the application of DEA in cloud environment. Kumar (2014) proposed a method for performance evaluation of cloud services based on DEA, AHP and technique for order preference by similarity to ideal solution (TOPSIS). Wang (2015) presented a nonparametric DEA for evaluating the relative efficiency of IaaS services. In this approach cloud services are described based on functional requirements such as storage, Memory and CPU (Filiopoulou et al. 2018). Filiopoulou et al. (2018) proposed a DEA input-oriented model for performance measurement of cloud services based on both functional and non-functional parameters such as reliability, security and cloud management features. They believe that both functional and nonfunctional parameters play key roles in enhancing cloud services and need to be taken into account in performance evaluation of CSPs. While functional parameters define the straightforward cloud services, non-functional parameters denote to the expected quality of services and show the constraints need to operate under which services (Filiopoulou et al. 2018).

As the literature shows, in spite of, the numerous advantages of DEA as a powerful approach in efficiency evaluation of DMUs, their application in the cloud computing is scarce.

\section{PROPOSED METHODOLOGY: NETWORK} DATA ENVELOPMENT ANALYSIS FOR EVALUATING CLOUD SERVICE

\section{PERFORMANCE (CSP)}

Data Envelopment Analysis (DEA) is one of the most common techniques for performance evaluation of decision-making units. DEA is a multi-criteria decision method (MCDM) for measuring the efficiency of a set of homogenize decision making units (DMUs) that convert multiple inputs into multiple outputs (Kazemi Matin et al. 2014). The two basic DEA models are Charnes, Cooper and Rhoades (1978) model assuming constant returns to scale (CRS) and the Banker, Charnes and Cooper (1984) model considering variable returns to scale (VRS). DEA models have three orientations: input-oriented, output-oriented and non-oriented. Input-oriented measure are used to examine if a DMU under evaluation can decrease its inputs while keeping its outputs level. Output-oriented measure are used to examine if a DMU under evaluation can increase its outputs while keeping its inputs level. Nonoriented measures provides some and allow changes in both inputs and outputs levels of DMU under evaluation (Emrouznejad and Amin, 2009). 
In spite of the considerable advantages of conventional DEA models, they are unable to measure the efficiency of DMUs with network structures (Lewis and Sexton, 2004). Färe and Grosskopf (1996) were among the first to take into account the internal structure of the DMUs in performance measurement and proposed network activity analysis models (Despotis, 2016). Considering the internal structure of DMUs, Lewis and Sexton (2004) proposed a network DEA model that could be either an input-oriented or outputoriented and allows for any of the four standard assumptions regarding returns to scale in any SubDMU, and makes adjustments for site characteristics in each Sub-DMU. Kao and Hwang (2008) considered the series relationship of the two divisions and showed that the overall efficiency is a product of the efficiencies of these two divisions. Liang et al. (2008) examined and extended the twostage processes where all outputs from stage one are the inputs to stage two using game theory concepts (Lozano, 2012). Li et al. (2012) extended the model proposed by Liang et al. (2008). They considered a two-stage DEA model in which the outputs of stage one and additional inputs to stage two are assumed as inputs for stage two. Moreno and Lozano (2014) proposed a network DEA model to measure the performance of NBA basketball teams. They also compared their obtained results with the single-stage DEA approach. Huang (2018) proposed a hybrid network DEA to assess the performance of tourism supply chains. Badiezadeh et al. (2018) presented a network DEA model to calculate optimistic and pessimistic efficiency.
The input orinted and output orinted SBM models are given below respetively.

\section{Model 1}

$\rho_{I}^{*}=\min _{\lambda, s^{-}, s^{+}} 1-\frac{1}{m} \sum_{i=1}^{m} \frac{s_{i}^{-}}{x_{i o}}$,

s.t.

$x_{i o}=\sum_{j=1}^{n} x_{i j} \lambda_{j}+s_{i}^{-} \quad(i=1, \ldots, m)$,

$y_{\text {ro }}=\sum_{j=1}^{n} y_{r j} \lambda_{j}-s_{i}^{+} \quad(r=1, \ldots, s)$,

$\sum_{j=1}^{n} \lambda_{j}=1$

$\lambda_{j} \geq 0(\forall j), \quad s_{i}^{-} \geq 0(\forall j), \quad s_{r}^{+} \geq 0(\forall j)$,

Model 2

$\frac{1}{\rho_{o}^{*}}=\max _{\lambda, s^{-}, s^{+}} 1+\frac{1}{s} \sum_{r=1}^{s} \frac{s_{r}^{+}}{x_{i o}}$,

s.t.

$x_{i o}=\sum_{j=1}^{n} x_{i j} \lambda_{j}+s_{i}^{-} \quad(i=1, \ldots, m)$,

$y_{r o}=\sum_{j=1}^{n} y_{r j} \lambda_{j}-s_{i}^{+} \quad(r=1, \ldots, s)$,

$\sum_{j=1}^{n} \lambda_{j}=1$

$\lambda_{j} \geq 0(\forall j), \quad s_{i}^{-} \geq 0(\forall j), \quad s_{r}^{+} \geq 0(\forall j)$,

The following model measures the efficency of DMUs using the non-oriented SBM model.

$\underline{\text { Model } 3}$

$\rho_{I o}^{*}=\min _{\lambda, s^{-}, s^{+}} \frac{1-\frac{1}{m} \sum_{i=1}^{m} \frac{s_{i}^{-}}{x_{i o}}}{1+\frac{1}{s} \sum_{r=1}^{s} \frac{s_{r}^{+}}{x_{i o}}}$,

s.t.

$x_{i o}=\sum_{j=1}^{n} x_{i j} \lambda_{j}+s_{i}^{-} \quad(i=1, \ldots, m)$,

$y_{r o}=\sum_{j=1}^{n} y_{r j} \lambda_{j}-s_{i}^{+} \quad(r=1, \ldots, s)$,

$\sum_{j=1}^{n} \lambda_{j}=1$

$\lambda_{j} \geq 0(\forall j), \quad s_{i}^{-} \geq 0(\forall j), \quad s_{r}^{+} \geq 0(\forall j)$,

According to the formulations in Tone and Tsutsui (2009), the SBM network model not only is able to 
estimate the overall DMU efficiency, it is also able to estimate divisional efficiency. The relative efficiency technique that is utilized in this study is the non-oriented network slacks-based measure (SBM) for overall and divisional efficiency. The estimated efficiency for a CSP (DMU) is based on both input and output slacks (inefficiencies).

The non-oriented network SBM model is defined as follows:

Model 4

$\rho_{o}^{*}=\min _{\lambda^{k}, s^{k-}, s^{k+}} \frac{\left[1-\frac{1}{m_{k}}\left(\sum_{i=1}^{m_{k}} \frac{s_{i}^{k-}}{x_{i o}^{k}}\right)\right]}{\left[1+\frac{1}{r_{k}}\left(\sum_{r=1}^{r_{k}} \frac{s_{r}^{k+}}{y_{r o}^{k}}\right)\right]}$

$x_{o}^{k}=x_{i j}{ }^{k} \lambda^{k}+S^{k-} \quad(k=1, \ldots, K)$,

$y_{o}^{k}=y_{i j}{ }^{k} \lambda^{k}-S^{k+} \quad(k=1, \ldots, K)$,

$z_{o}^{(k, h)}=z_{i j}{ }^{k, h} \lambda^{h} \quad(\forall(k, h))$,

$z_{o}^{(k, h)}=z_{i j}{ }^{k, h} \lambda^{k} \quad(\forall(k, h))$,

$e \lambda^{k}=1 \quad(k=1, \ldots, K)$,

$\lambda^{k} \geq 0, \quad S^{k-} \geq 0, \quad S^{k+} \geq 0, \quad \forall k$,

We deal with $n$ DMUs $j=(1, \ldots, n)$ consisting of $\mathrm{K}$ divisions $(k=1, \ldots, K)$. Let $m_{k}$ and $r_{k}$ be the numbers of inputs and outputs to Division $k$, respectively. We denote the link leading from Division $k$ to Division $\mathrm{h}$ by $(k, h)$ and the set of links by $\mathrm{L}$. The observed data are $\left\{x_{j}^{k} \in R_{+}^{m_{k}}\right\}(j=$ $1, \ldots, n ; k=1, \ldots, K$ ) (input resources to $D M U_{j}$ at Division $\mathrm{k}), \quad\left\{y_{j}^{k} \in R_{+}^{r_{k}}\right\}(j=1, \ldots, n ; k=$ $1, \ldots, K$ ) (output products from $D M U_{j}$ at Division $k) \quad$ and $\quad\left\{z_{j}^{(k, h)} \in R_{+}^{t_{(k, h)}}\right\}(j=1, \ldots, n ;(k, h))$ (linking intermediate products from Division k to Division $h$ ) where $t_{(k, h)}$ is the number of items in Link $(k, h)$.

Also the non-oriented network SBM model's divisional efficiency is defined as follows:

$\underline{\text { Model } 5}$ $\rho_{k}$

$$
=\frac{1-\frac{1}{m_{k}}\left(\sum_{i=1}^{m_{k}} \frac{s_{i}^{k-*}}{x_{i o}^{k}}\right)}{1+\frac{1}{r_{k}}\left(\sum_{r=1}^{r_{k}} \frac{s_{i}^{k-*}}{x_{i o}^{k}}\right)}
$$

$=1, \ldots, K)$

The network SBM model is a composite formulation of the input-oriented and outputoriented SBM models proposed by Tone (2001). Generally, the SBM network model can be formulated under input, output and non-oriented forms, and can be designated as constant returns to scale (CRS) or variable returns to scale (VRS) as demonstrated later in this article.

SBM is units-invariant and can accept variables measured in various dimensions, i.e. the optimal solution is not affected by variables measured in dissimilar units. Nonetheless, the SBM model is not translation invariant, denoting that the optimal solution will be impacted by data transformation that may be undertaken by researchers during the data collection. Lastly, SBM can accept all types of data including negative, zero or positive numbers for output variables; however it accepts only semipositive data such as zero or positive numbers for input variables (Avkiran, 2015, see also Cooper et al., 2006).

\section{EVALUATION OF OUR PROPOSED}

\section{METHODOLOGY}

This section details our proposed methodology that is used for ranking and selecting CSPs. In this study, the selected companies are considered to be DMUs. The condition of homogeneity has also been met in order to ensure a fair and comparable evaluation. The research sample included the top 82 IaaS providers. Of these, 18 CSPs, including Amazon Web Services (AWS), Microsoft Azure, International Business Machines (IBM) SoftLayer, etc. had the most data-based QoS indicators and 
relatively speaking the others did not have much ${ }^{2}$. Hence, we removed the CSPs which had incomplete data (i.e.., missing values for a number of QoS parameters) so the final research sample had complete data for all indicators after excluding the missing values and incomplete indicators. Owing to the research limitations and ensuring the accuracy of data, we undertook the data collection manually, without the assistance of software. Data were collected online using websites, telephone calls, chats and personal contact with the sales employees who offered IaaS between August 2017 and March 2018. The input and output indicators in this study are the pivotal factors in evaluating the proposed methodology and selecting CSPs, based on QoS. QoS signifies a number of accepted nonfunctional attributes of services, including availability, latency, price and security in the cloud domain. Several state-of-the-art service evaluation and selection approaches use QoS values for the evaluation and selection of cloud services. Descriptive statistics on data for the crucial input and output variables adjusted for computing services in IaaS are shown in Table 1. Two inputs are considered in this study, price and latency. The case study outputs consisting of six items, memory, storage, data transfer, CPU, availability and the number of security certifications.

Table 1. Attributes of the 18 cloud service providers (CSPs) and their values

\begin{tabular}{|c|c|c|c|c|c|c|c|c|}
\hline \multirow[t]{2}{*}{ CSPs } & \multicolumn{2}{|c|}{ Inputs } & \multicolumn{3}{|c|}{$\begin{array}{c}\text { Intermediate inputs/ } \\
\text { outputs }\end{array}$} & \multicolumn{3}{|c|}{ Outputs } \\
\hline & $\begin{array}{c}\text { Price } \\
(\text { monthly } / \$)\end{array}$ & $\begin{array}{l}\text { Latency } \\
(\mathrm{ms})\end{array}$ & $\begin{array}{l}\text { Memory } \\
\text { (GB) }\end{array}$ & $\begin{array}{l}\text { Storage } \\
\text { (GB) }\end{array}$ & $\mathrm{CPU}$ & $\begin{array}{c}\text { Availability } \\
\%\end{array}$ & $\begin{array}{l}\text { The number of security } \\
\text { certifications }\end{array}$ & $\begin{array}{l}\text { Data } \\
\text { transfer } \\
\text { (TB) }\end{array}$ \\
\hline 1 & 80 & 433 & 8 & 80 & 2 & 100 & 5 & 5 \\
\hline 2 & 140.79 & 49 & 7 & 100 & 2 & 99.9898 & 3 & 3.2 \\
\hline 3 & 80 & 46 & 8 & 80 & 4 & 100 & 4 & 5 \\
\hline 4 & 80 & 39 & 8 & 200 & 6 & 99.9453 & 1 & 8 \\
\hline 5 & 158 & 45 & 2 & 500 & 4 & 100 & 3 & 0.5 \\
\hline 6 & 110 & 41 & 4 & 100 & 2 & 99.9987 & 4 & 3 \\
\hline 7 & 150 & 68 & 16 & 384 & 6 & 99.994 & 4 & 8 \\
\hline 8 & 160 & 32 & 16.384 & 170 & 8 & 99.9993 & 1 & 2 \\
\hline 9 & 156.24 & 40 & 2 & 40 & 2 & 100 & 4 & 10 \\
\hline 10 & 87.88 & 46 & 2.048 & 90 & 3 & 99.9968 & 2 & 3 \\
\hline 11 & 16.65 & 152 & 0.5 & 20 & 1 & 99.8938 & 1 & 0.5 \\
\hline 13 & 15 & 40 & 0.5 & 10 & 1 & 99.9303 & 1 & 3 \\
\hline 14 & 79 & 71 & 8 & 80 & 2 & 100 & 2 & 5 \\
\hline 14 & 83.00 & 62 & 7 & 100 & 1 & 100 & 4 & 3 \\
\hline 15 & 64.95 & 62 & 4 & 250 & 2 & 100 & 1 & 3 \\
\hline 16 & 5 & 45 & 1 & 20 & 1 & 99.9876 & 1 & 1 \\
\hline 17 & 219 & 46 & 8 & 300 & 8 & 99.7473 & 2 & 10 \\
\hline 18 & 82.60 & 32 & 2 & 100 & 2 & 99.999 & 1 & 18 \\
\hline
\end{tabular}

Sarkis (2007) stated DEA method and its appropriate applications are greatly dependent on the data set that is used as an input to the productivity model. Although there are numerous models based on DEA, some data have certain characteristics that may not be acceptable for the

${ }^{2}$ Please note, as requested by CSPs we removed the names of the CSPs in this study. 
execution of DEA models. One of them is normalized data. To be more precise, one of the best ways to make sure there is not much imbalance in the data sets is to ensure that they are at the same or similar magnitude. A way to do this is to mean normalize the data. There are two steps in the mean normalizing process: first, finding the mean of the data set for each input and output; and second to divide each input or output by the mean for that specific factor. The normalized data are given in Table 2.

Table 2. The normalized data for the attributes of the 18 CSPs

\begin{tabular}{|c|c|c|c|c|c|c|c|c|}
\hline \multirow[t]{2}{*}{ CSPs } & \multicolumn{2}{|c|}{ Inputs } & \multicolumn{3}{|c|}{$\begin{array}{c}\text { Intermediate inputs/ } \\
\text { outputs }\end{array}$} & \multicolumn{3}{|c|}{ Outputs } \\
\hline & $\begin{array}{c}\text { Price } \\
\text { (monthly/\$) }\end{array}$ & $\begin{array}{l}\text { Latency } \\
(\mathrm{ms})\end{array}$ & $\begin{array}{l}\text { Memory } \\
\text { (GB) }\end{array}$ & $\begin{array}{l}\text { Storage } \\
\text { (GB) }\end{array}$ & CPU & $\begin{array}{c}\text { Availabilit } \\
y\end{array}$ & $\begin{array}{l}\text { The number of } \\
\text { security } \\
\text { certifications }\end{array}$ & $\begin{array}{l}\text { Data } \\
\text { transfer } \\
\text { (TB) }\end{array}$ \\
\hline 1 & 0.814 & 5.777 & 1.378 & 0.548 & 0.631 & 1.0002 & 2.045 & 0.986 \\
\hline 2 & 1.433 & 0.653 & 1.206 & 0.685 & 0.631 & 1.0001 & 1.227 & 0.631 \\
\hline 3 & 0.814 & 0.613 & 1.378 & 0.548 & 1.263 & 1.0002 & 1.636 & 0.986 \\
\hline 4 & 0.814 & 0.520 & 1.378 & 1.371 & 1.894 & 0.9997 & 0.409 & 1.578 \\
\hline 5 & 1.608 & 0.600 & 0.344 & 3.429 & 1.263 & 1.0002 & 1.227 & 0.098 \\
\hline 6 & 1.119 & 0.547 & 0.689 & 0.685 & 0.631 & 1.0002 & 1.636 & 0.592 \\
\hline 7 & 1.527 & 0.907 & 2.757 & 2.634 & 1.894 & 1.0002 & 1.636 & 1.578 \\
\hline 8 & 1.628 & 0.426 & 2.823 & 1.166 & 2.526 & 1.0002 & 0.409 & 0.394 \\
\hline 9 & 1.590 & 0.533 & 0.344 & 0.274 & 0.631 & 1.0002 & 1.636 & 1.973 \\
\hline 10 & 0.894 & 0.613 & 0.352 & 0.617 & 0.947 & 1.0002 & 0.818 & 0.592 \\
\hline 11 & 0.169 & 2.028 & 0.086 & 0.137 & 0.315 & 0.9992 & 0.409 & 0.098 \\
\hline 13 & 0.152 & 0.533 & 0.086 & 0.068 & 0.315 & 0.9995 & 0.409 & 0.592 \\
\hline 14 & 0.804 & 0.947 & 1.378 & 0.548 & 0.631 & 1.0002 & 0.818 & 0.986 \\
\hline 14 & 0.844 & 0.827 & 1.206 & 0.685 & 0.315 & 1.0002 & 1.636 & 0.592 \\
\hline 15 & 0.661 & 0.827 & 0.689 & 1.714 & 0.631 & 1.0002 & 0.409 & 0.5921 \\
\hline 16 & 0.050 & 0.600 & 0.172 & 0.137 & 0.315 & 1.0001 & 0.409 & 0.197 \\
\hline 17 & 2.229 & 0.613 & 1.378 & 2.057 & 2.526 & 0.9977 & 0.818 & 1.973 \\
\hline 18 & 0.840 & 0.426 & 0.344 & 0.685 & 0.631 & 1.0002 & 0.409 & 3.552 \\
\hline
\end{tabular}

\section{RESULTS AND DISCUSSION}

First, we calculate the efficiency scores for 18 CSPs using model 3 with the assumptions of CRS and VRS with two inputs and six outputs avoiding the links between divisions. This is shown in the last two columns in Table 3. We also calculated the efficiency scores of the CSPs using the network SBM model, shown in columns 2, 3, and 4 in Table 3. As seen in Figures 1, the SBM (VRS) scores could not distinguish between the cloud service providers as their value is always 1 . The
SBM (CRS) can partly discern differences between CSPs. But it is clear from this Figure that the network SBM model can distinguish between the CSPs, this is due to considering the internal links in the networks which are ignored in the standard DEA models.

In general, the efficiency scores using conventional DEA models tend to be higher than those of the network DEA ones. This is mainly due to differences between the number of inputs and outputs in the two approaches and the fact that the 
standard DEA models ignore the internal structure

of DMUs.

Table 3. The results

\begin{tabular}{cccccc}
\hline CSPs & Stage 1 efficiency & Stage 2 efficiency & $\begin{array}{c}\text { Network SBM } \\
\text { (Overall efficiency) }\end{array}$ & $\begin{array}{c}\text { SBM } \\
\left(\mathbf{C R S}^{3}\right)\end{array}$ & SBM $\left(\mathbf{V R S}^{4}\right)$ \\
\hline 1 & 0.517 & 1 & 0.758 & 0.1271652 & 1 \\
2 & 0.642 & 0.503 & 0.572 & 0.3300747 & 1 \\
3 & 0.896 & 0.750 & 0.823 & 1 & 1 \\
4 & 1 & 0.468 & 0.734 & 1 & 1 \\
5 & 1 & 0.134 & 0.567 & 1 & 1 \\
6 & 0.690 & 0.562 & 0.626 & 1 & 1 \\
7 & 1 & 0.923 & 0.961 & 1 & 1 \\
8 & 1 & 0.435 & 0.717 & 1 & 1 \\
9 & 0.587 & 1 & 0.793 & 1 & 1 \\
10 & 0.662 & 0.421 & 0.541 & 0.2949357 & 1 \\
11 & 0.298 & 0.375 & 0.336 & 0.1259881 & 1 \\
12 & 1 & 1 & 1 & 1 & 1 \\
13 & 0.753 & 0.600 & 0.676 & 0.3853003 & 1 \\
14 & 0.7213567 & 1 & 0.860 & 0.3615719 & 1 \\
15 & 1 & 0.360 & 0.680 & 1 & 1 \\
16 & 1 & 1 & 1 & 1 & 1 \\
17 & 1 & 0.749 & 0.874 & 1 & 1 \\
18 & 1 & 1 & 1 & 1 & 1 \\
\hline
\end{tabular}

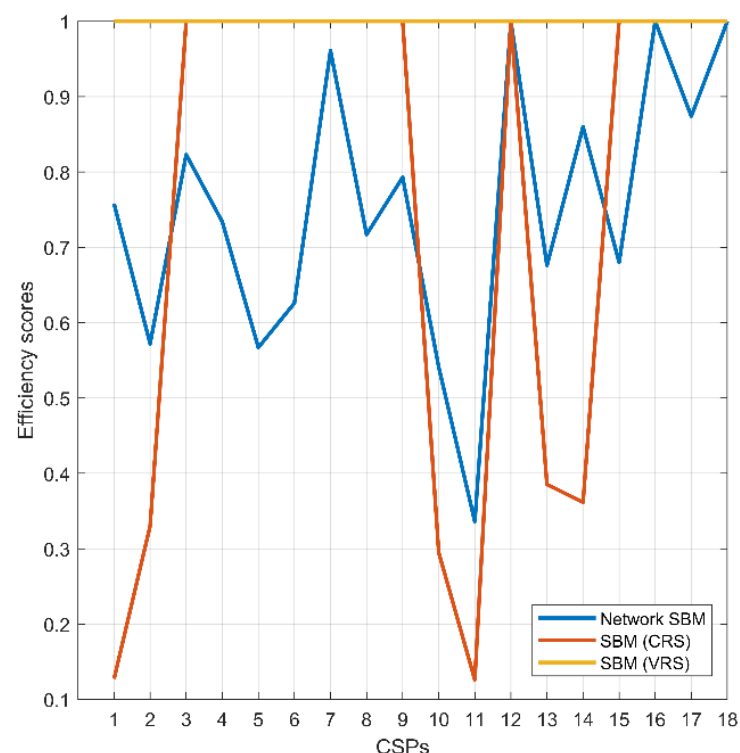

Figure 1. The obtained results using network DEA, SBM (CRS) and SBM (VRS).
As previously mentioned, the traditional DEA models do not consider the links and the gap between the conventional and network models implies the "networking effects". As Tone and Tsutsui (2009) discussed, the VRS models have at least one efficient DMU within each division. In this case study, there are 11 efficient CSPs out of 18. However, CSP 12, 16 and 18 are the only CSPs that are efficient in both stages one and two. This means the other CSPs need to improve their efficiency at least in one stage in order to be efficient. Column 5 in Table 3 shows that CSPs 1 and 11 have the lowest efficiency value compared to the other CSPs. These inefficiencies are mainly

\footnotetext{
${ }^{3}$ Constant returns to scale. For more details, please see Cooper et al. (2011).

${ }^{4}$ Variable returns to scale. For more details, please see Avkiran, (2015).
} 
related to their high latency. However, in stage two, CSP 5 had the lowest efficiency value mainly due to having a lower amount of data transfer compared to the other CSPs.

\section{IMPLICATIONS}

In this section we discuss the implications of the results obtained and documented in this paper for both researchers and practitioners.

\subsection{IMPLICATIONS FOR RESEARCHERS}

Despite the rapid growth in the cloud market, no research has been carried out on the performance measurement of CSPs by applying DEA and network DEA. This is the first work that carries out an empirical study on the application of network DEA to measure the performance of CSPs that provide IaaS. This study shows that network DEA differentiates between the CSPs that are evaluated as efficient units using the DEA method. This can justify the efficiency of network DEA as a powerful decision-making tool. In addition, the application of network DEA models has not been investigated in the cloud computing area and is in its infancy, therefore this study is the first attempt in this area and will hopefully encourage researchers to develop and apply network DEA models that are appropriate for solving the existing problems in cloud computing area. This study uses network DEA method as a tool for measuring the efficiency of CSPs. This will assist researchers to more precisely examine the performance evaluation of CSPs. Also, it can help researchers to define input, intermediate and output variables in the performance measurement of CSPs with the intention being to determine the leading and lagging indicators.

\subsection{IMPLiCATIONS FOR PRACTITIONERS}

Today, a lot of businesses choose to use IaaS as they recognise its competitive advantage. The model applied in this study can assist managers and decision makers to select the CSP which provides the optimal IaaS. Given that the initial investment in using cloud computing services such as IaaS can be costly and time-consuming, performance measurement techniques including DEA and network DEA can be an appropriate decision-support system. In addition, the proposed model can be applied to solve various evaluation and selection problems related to cloud services.

The results of this study suggest that network DEA can effectively measure the efficiency of CSPs in separate stages, based on QoS indicators. Furthermore, it can help CSPs to identify their inefficiencies in each stage and address these by making the right decisions. This, in turn, helps CSPs to ensure that the select the right CSP and in turn ensure that there is no disruption to their business by selecting the best CSP.

\section{CONClUSION AND DIRECTION FOR FUTURE RESEARCH}

The performance efficiency of CSPs in a highly competitive environment with consideration of QoS indicators is one of the most significant issues for cloud service customers and providers.

This study illustrates how network DEA, which is a benchmark frontier technique, can be applied in evaluating the performance of CSPs. The findings 
of this article demonstrate the advantages of network DEA in determining the efficiency of each stage as well as the overall efficiency of CSPs. In addition, the model is able to identify the inefficient aspects of the CSPs which need to be improved. This is a key advantage of the network DEA approach over all the other existing approaches. The current study proposes a rigorous technique for the assessment of the efficiency of CSPs for the first time and can be used as a reference for researchers and practitioners seeking to develop other DEA and network DEA models, to evaluate the performance of CSPs and, most importantly, to address other significant issues in the cloud domain.

In the future, the application of non-deterministic techniques, such as the fuzzy technique in DEA network models, will be investigated. In addition, the QoS-index utilized in this study is only based on eight attributes due to a difficulty in accessing complete data sets. It is critical also important to satisfy the main DEA restriction that limits the number of DMUs to 3 times the number of indicators. These limit the ability of the applied model to rank CSPs appropriately. Therefore, another future direction of this study is to develop new DEA or network DEA models that are able to tackle this problem in an appropriate way. Finally, due to the limited access to the data sets across different time periods, the dynamic nature of the efficiency evaluation of CSPs is not been considered in this study. The authors believe that if they had access to datasets of CSP for different time periods, this problem could be tackled by developing a dynamic DEA or a dynamic network DEA.

\section{REFERENCES}

[1] Alabool, H. M., and Mahmood, A. K. B. (2016). "A Novel Evaluation Framework for Improving Trust Level of Infrastructure as a Service", Cluster Computing, Vol. 19, No. 1, pp. 389-410.

[2] Azadi. M., and Farzipoor Saen, R. (2013). "A Combination of QFD and Imprecise DEA with Enhanced Eussell Graph Measure: A Case Study in Healthcare", Socio-Economic Planning Sciences, Vol. 47, No. 4, pp. 281-291.

[3] Azadi, M., Jafarian, M., Farzipoor Saen, R., and Mirhedayatian, S.M. (2015). A New Fuzzy DEA Model for Evaluation of Efficiency and Effectiveness of Suppliers in Sustainable Supply Chain Management Context, Computers \& Operations Research, Vol. 54, pp. 274-285.

[4] Atmaca, T., Begin, T., Brandwajn, A., and CastelTaleb. H. (2016). "Performance Evaluation of Cloud Computing Centers with General Arrivals and Service", IEEE Transactions on Parallel and Distributed Systems, Vol. 27, No. 8, pp. 23412348.

[5] Avkiran, N. K. (2015). "An Illustration of Dynamic Network DEA in Commercial Banking Including Robustness Tests", Omega, Vol. 55, pp. 141-150.

[6] Badiezadeh, T., Farzipoor Saen, R., and Samavati, T. (2018). "Assessing Sustainability of Supply Chains by Double Frontier Network DEA: A Big Data Approach", Computers \& Operations Research, Vol. 98, pp. 284-290.

[7] Banker, R. D., Charnes, A., and Cooper. W. W. (1984). "Models for Estimation of Technical and Scale Inefficiencies in Data Envelopment Analysis", Management Science, Vol.27, No.12, pp.1370-1382.

[8] Charnes, A., Cooper, W. W., and Rhodes, E. (1978). "Measuring the Efficiency of Decision Making Units", European Journal of Operational Research, Vol. 2, No. 6, pp.429-444.

[9] Choudhury, P., Sharma, M., Vikas, K., Pranshu, T., and Satyanarayana, V. (2012). "Service Ranking Systems for Cloud Vendors", Advanced Materials Research, Vol. 433-440, pp. 3949-3953.

[10] Cooper W, W., Seiford L. M, and Tone, K. (2006) "Introduction to Data Envelopment Analysis and Its Uses". New York: Springer; http://au.wiley.com/WileyCDA/Wiley Title/productCd-111996752X.html. 
[11] Cooper, W. W., Seiford, L. M., and Zhu, J. (2011). Handbook on Data Envelopment Analysis. In Chapter 1: Data Envelopment Analysis (pp. 1-39).

[12] Despotis, D. K., Sotiros, D., and Koronakos, G. (2016). "A Network DEA Approach for Series Multi-stage Processes", Omega, Vol. 61, pp. 3548.

[13] Duan, Q. (2017). "Cloud service performance evaluation: status, challenges, and opportunities a survey from the system modeling perspective", Digital Communications and Networks, Vol. 3, pp. 101-111.

[14] Elgendy, I. A., Zhang, W. Z., Liu, C. Y., and Hsu, C. H. (2018). "An Efficient and Secured Framework for Mobile Cloud Computing," IEEE Transactions on Cloud Computing. doi: 10.1109/TCC.2018.2847347.

[15] Emrouznejad, A., and Amin, G. R. (2009). DEA models for ratio data: convexity consideration. Applied Mathematical Modelling, Vol. 1, pp. 486498. https://doi.org/10.1016/j.apm.2007.11.018.

[16] Emrouznejad, A., Gholami, R., and Cabanda, E. (2010). "An Alternative Measure of the ICTOpportunity Index", Information \& Management, Vol. 47, No. 4, pp. 246-254.

[17] Färe, R., and Grosskopf, S., (1996). "Productivity and Intermediate Products: a Frontier Approach", Economics Letters, Vol. 50, No. 1, pp. 65-70.

[18] Fathi, A., and Reza Farzipoor Saen, R. (2018). “A Novel Bidirectional Network Data Envelopment Analysis Model for Evaluating Sustainability of Distributive Supply Chains of Transport Companies", Journal of Cleaner Production, Vol. 184, pp. 696-708.

[19] Filiopoulou E., Mitropoulou, P., Lionis, N., and Michalakelis, C. (2018), "On the efficiency of cloud providers: A DEA approach incorporating categorical variables," IEEE Transactions on Cloud Computing, doi: 10.1109/TCC.2018.2850889.

[20] Garag, S. K., Verstegg, S. and Buyya. R. (2013). "A Framework for Ranking of Cloud Computing Services", Future Generation Computer Systems, Vol. 29, No. 4, pp. 1012-1023.

[21] Ghosh, N., Ghosh, K. S., and Das, S. K. (2015). 'SelCSP: A framework to facilitate selection of cloud service providers', IEEE Transactions on Cloud Computing, Vol. 3, No. 1, pp. 66-79. DOI: 10.1109/TCC.2014.2328578.

[22] Huang, C, W. (2018). “Assessing the Performance of Tourism Supply Chains by using The Hybrid Network Data Envelopment Analysis Model", Tourism Management, Vol. 65, pp. 303-316.

[23] Huang C. Y., Hsu P. C., and Tzeng G. H. (2012). "Evaluating Cloud Computing Based
Telecommunications Service Quality Enhancement by Using a New Hybrid MCDM Model". In: Watada J., Watanabe T., Phillips-Wren G., Howlett R., Jain L. (eds) Intelligent Decision Technologies. Smart Innovation, Systems and Technologies, Vol 15. Springer, Berlin, Heidelberg.

[24] Kao, C., and Hwang, S. N. (2008). "Efficiency Decomposition in Two-Stage Data Envelopment Analysis: An Application to Non-Life Insurance Companies in Taiwan", European Journal of Operational Research, Vol. 185, No. 1, pp. 418429.

[25] Kazemi Matin, R., Amin, G. R., and Emrouznejad, A. (2014). A modified Semi-Oriented Radial Measure for target setting with negative data. Measurement, Measurement, Vol. 54, pp. 152-158.

[26] Kumar, S. (2014). "Evaluating Cloud Services based on DEA, AHP and TOPSIS", D.G.R. Gangadharan, Institute of Development and Research in Banking Technology, Hyderabad.

[27] Kumar, N., and Agarwal, S (2014). "QoS Based Cloud Service Provider Selection Framework, Research Journal of Recent Sciences", Vol. 3, pp. 7-12.

[28] Lewis, H. F., and Sexton, T. R., (2004). "Network DEA: Efficiency Analysis of Organizations with Complex Internal Structure", Computers \& Operations Research, Vol. 31, No. 9, pp. 13651410.

[29] Li, Y., Chen, Y., Liang, L., and Xie, J. (2012). "DEA models for Extended Two-Stage Network Structures", Omega, Vol. 40, No. 5, pp. 611-618.

[30] Liang, L., Cook, W. D., and Zhu, J. (2008). "DEA Models for Two-Stage Processes: Game Approach and Efficiency Decomposition", Naval Research Logistics, Vol. 55, No. 7, pp. 643-653.

[31] Lozano, S. (2012). "Information sharing in DEA: A cooperative game theory approach, European Journal of Operational Research, Vol, 222, No, 3, pp. 558-565.

[32] Martínez-Núñez, M., and Pérez-Aguiar, W. S. (2014). "Efficiency Analysis of Information Technology and Online Social Networks Management: An Integrated DEA-Model Assessment", Information \& Management, Vol. 51, No. 6, pp. 712-725.

[33] Menzel, M., Ranjan, R., Wang, L., Khan, S. U., and Chen, J. (2014). "Cloudgenius: A Hybrid Decision Support Method for Automating the Migration of Web Application Clusters to Public Clouds". IEEE Transactions on Computers. Vol. 64, No. 5, pp. 1336-1348.

[34] Mirhedayatian, S. M., Azadi, M., and Farzipoor Saen, R. (2014). "A Novel Network Data Envelopment Analysis Model for Evaluating 
Green Supply Chain Management”, International Journal of Production Economics, Vol. 147, pp. 544-554.

[35] Moreno, P., and Lozano, S. (2014). "A Network DEA Assessment of Team Efficiency in the NBA, Annals of Operations Research, Vol. 214, pp. 99124.

[36] Rajarajeswari, C. S., and Aramudhan, M. (2015). "Ranking of Cloud Service Providers in Cloud", Journal of Theoretical and Applied Information Technology, Vol. 78, No. 2, pp. 212-218.

[37] Sarkis, J. (2007). "Preparing your data for DEA, in Modeling data irregularities and structural complexities in data envelopment analysis", 2007, Springer. p. 305-320.

[38] Sahri, S., Moussa, R., Long, D. D. E., and Benbernou, S (2014). "DBaaS-Expert: A Recommender for the Selection of the Right Cloud Database". Foundations of Intelligent Systems, pp. 315-324. Springer, Roskilde.

[39] Shao, B. B. M., and Lin, W. T. (2002). "Technical efficiency analysis of information technology investments: a two-stage empirical investigation", Information \& Management, Vol. 39, No. 5, pp. 391-401.

[40] Singh, S., and Sidhu, S. (2017). "Compliancebased Multi-dimensional Trust Evaluation System for determining trustworthiness of Cloud Service Providers", Future Generation Computer Systems, Vol. 67, pp. 109-132.

[41] Supriya, M., Sangeeta, K., and Patra, G. K. (2016). "Trustworthy Cloud Service Provider Selection Using Multi Criteria Decision Making Method", Engineering Letters, Vol. 24, No. 1, pp. 1-10.

[42] Tone, K. (2001). "A Slacks-Based Measure of Efficiency in Data Envelopment Analysis. "European Journal of Operational Research", Vol. 130, pp. 498-509.

[43] Tone, K., and Tsutsui M. (2009). "Network DEA: A Slacks-Based Measure Approach" European Journal of Operational Research 2009, Vol. 197, pp. 243-252.

[44] Wang, C. X. Y. M. X. (2015). A Non-Parametric Data Envelopment Analysis Approach for Cloud Services Evaluation.

[45] Widiarto, I., Emrouznejad, A., and Anastasakis, L. (2017). "Observing Choice of Loan Methods in Not-For-Profit Microfinance Using Data Envelopment Analysis", Expert Systems with Applications, Vol. 82, pp. 278-290.

Majid Azadi is a Research Scholar at University of Technology Sydney (UTS). In 2009, he received his MSc in Industrial Management in the field of Operations Research from Azad University, Science and Research Branch in Iran. He has published over 40 papers in many top-tier journals such as IJPE, COR, TRPE, SEPS, IJPR, ESWA and JORS among others. Majid was awarded a Citation of Excellence 2017 award by Literati for his paper published in International Journal of Production Economics (IJPE).

Ali Emrouznejad is a Professor and Chair in Business Analytics at Aston Business School, UK. $\mathrm{He}$ received his $\mathrm{PhD}$ in Operational Research and Systems from Warwick Business School, UK. He has published over 120 articles in top ranked journals such as European Journal of Operational Research, OMEGA, Computers and Operations Research, Information and Management, Journal of Operational Research Society, Annals of Operations Research and many more. Additionally, Professor Ali Emrouznejad is Editor of (1) Annals of Operations Research, (2) Associate Editor of RAIOR-Operations Research, (3) Associate Editor of Socio-Economic Planning Sciences, (4) Associate Editor of IMA journal of Management Mathematics.

Dr. Fahimeh Ramezani is a scholarly teaching fellow at University of Technology Sydney (UTS). Additionally, she is a core member of the Centre for Artificial Intelligence (CAI). Dr. Fahimeh Ramezani received her PhD degree from UTS in Software Engineering. Her research interests lie in the areas of cloud computing, decision support systems, and optimization. Fahimeh is the winner of "The Computer Journal Wilkes Award 2018" which is given once a year to the authors of the best paper published in the volume of The Computer Journal from the previous year, based on originality and quality of theme and treatment.

Dr. Farookh Khadeer Hussain is Associate professor at University of Technology Sydney (UTS). He received his PhD in Computer Science Engineering from Curtin University. Dr. Farookh Khadeer Hussain is Head of Discipline (Software Engineering) at UTS. In a 2012 article, published in MIS Quarterly vol. 36 iss. 4, he was listed fifth in the world for researchers in Business Intelligence. He has published over 100 articles in many top ranked journals such as Information Systems, The computer Journal, Future Generation Computer Systems, International journal of parallel programming among others. 